\title{
The Effect of Cognitive-Behavioral Therapy on Pain Intensity in Patients with Chronic Pain
}

Pirhossein Kolivand, Azadeh Nazari Mahin*, Robabeh Jafari

Shefa Neuroscience Research Center, Khatam Alanbia Hospital, Tehran, Iran

\section{A BSTRACT}

Introduction: Chronic pain is annoying and this may cause reduction of the patient's tolerance threshold. Patients suffering from chronic pain experience significant psychological symptoms. This study was aimed to investigate the effectiveness of behavioral-cognitive treatment on decreasing pain intensity in patients suffering from chronic pain. Materials and Methods: The sample of 30 patients diagnosed with chronic pain were divided into two groups, including 14 men and 16 women. Pain intensity evaluation questionnaire was used to collect data, the pre-test, post-test, and follow-up of both control and experimental groups were completed. Behavioral- cognitive treatment was performed during 8 sessions. Results: This study revealed that the mean pain intensity scores in post-test significantly decreased compared to pre-test values. Conclusion: Our results indicated that cognitive-behavioral treatment is effective on decreasing pain intensity in patient suffering from chronic pain.

\section{Key words:}

1. Chronic Pain

2. Cognitive Therapy

3. Patients

*Corresponding Author: Azadeh Nazari Mahin

E-mail: azadehnazari1364@gmail.com 


\title{
تأثير درمان شناختى -رفتارى بر شدت درد در بيماران با درد مزمن
}

\author{
"يير حسين كوليوند، آزاده نظرى مهيين"، ربابه جعفرى \\ مركز تحقيقات علوم اعصاب شفا، بيمارستان خاتمالانبياء، تهران، ايران
}

\section{Q}

مقدمه: درد مزمن آزاردهنده است و اين ممكن است باعث كاهش آستانئ تحمل بيمار شود. بيماران

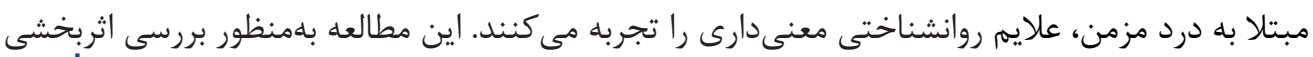

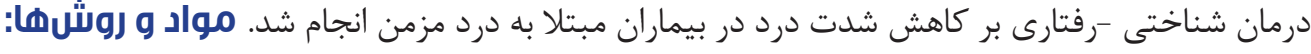

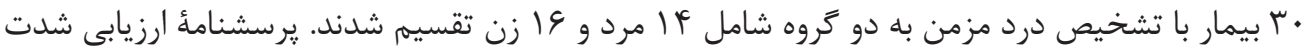

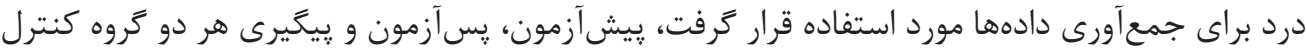

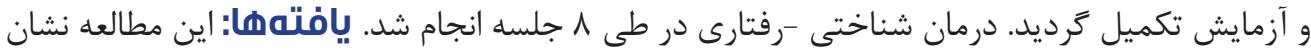

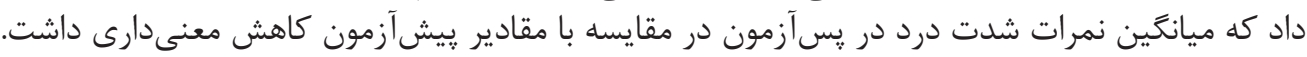

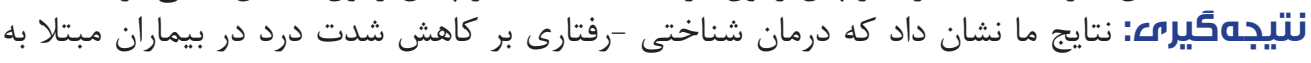




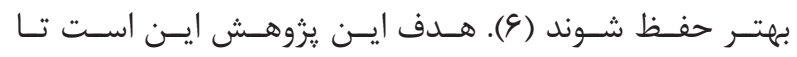

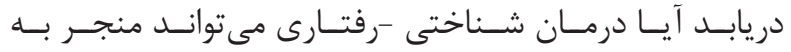

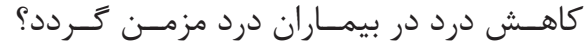

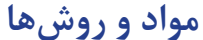

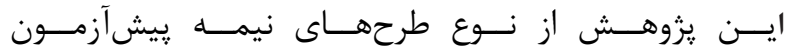

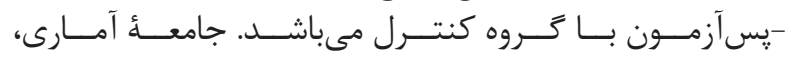

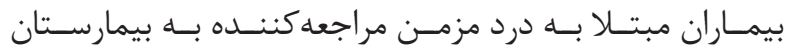

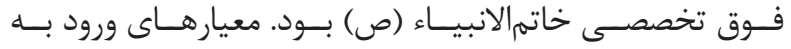

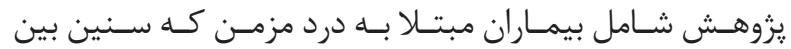

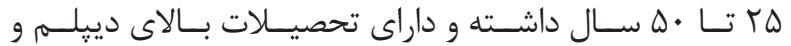

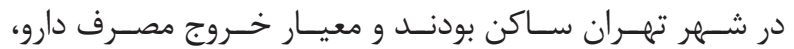

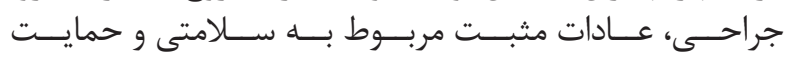

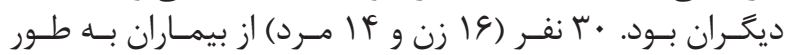

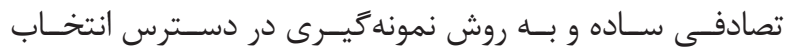

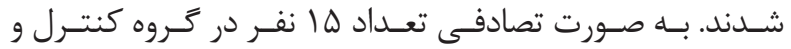

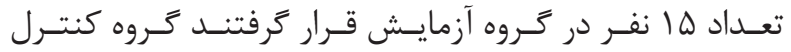

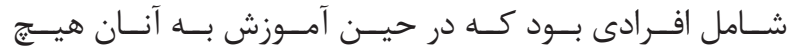

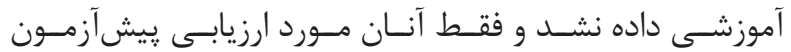

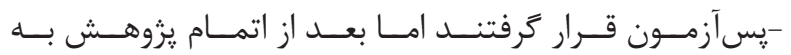

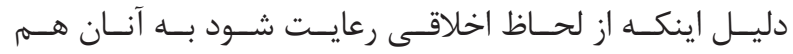

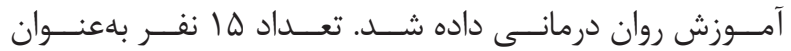

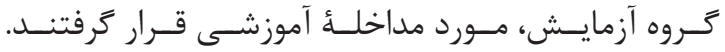

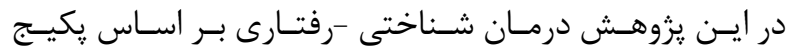

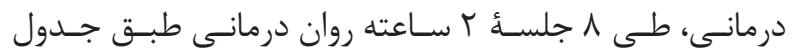

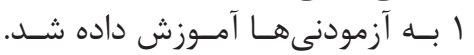

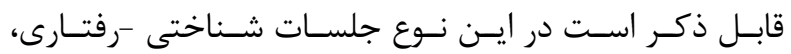

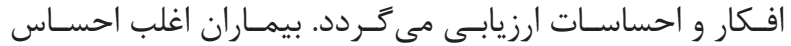

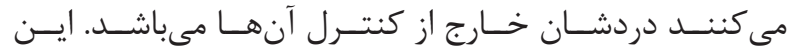

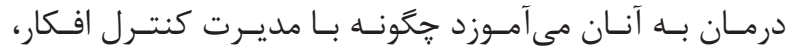

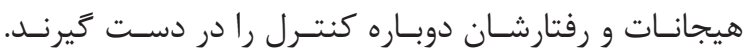

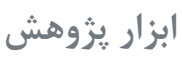

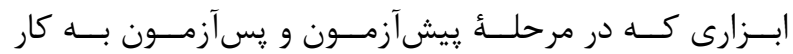

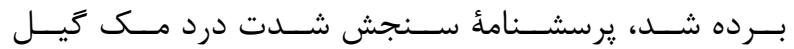

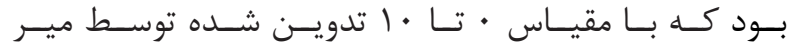

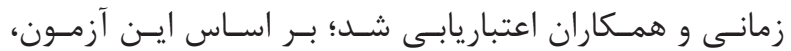

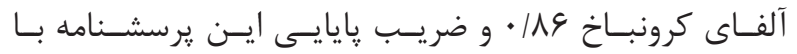

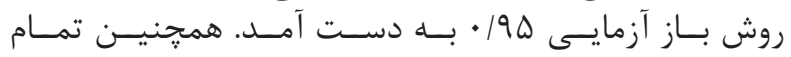

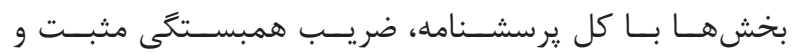

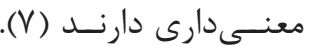

تجزيه و تحليل آمارى دارى داري

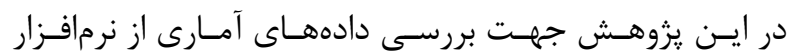

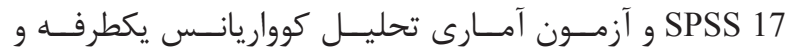

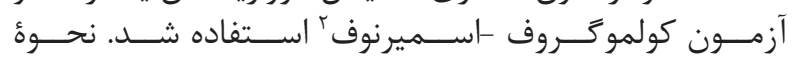

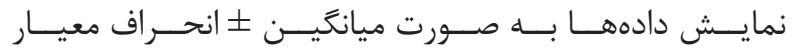

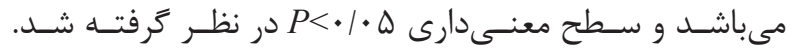

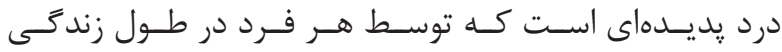

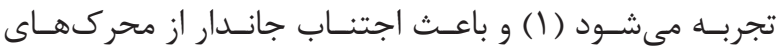

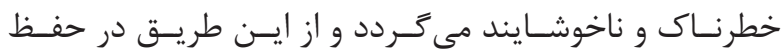

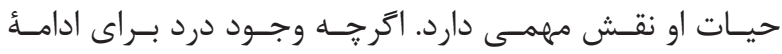

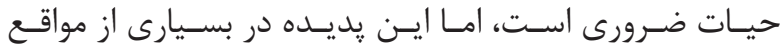

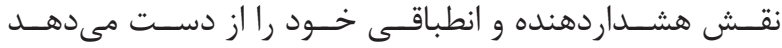

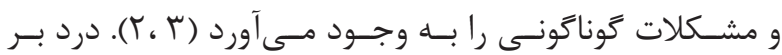

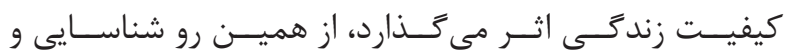

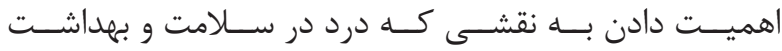

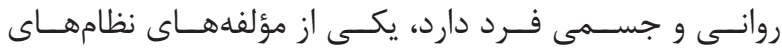

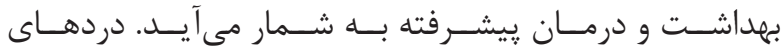

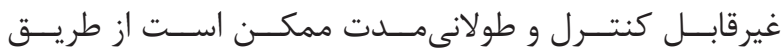

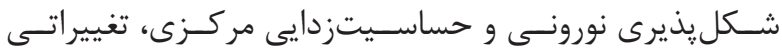

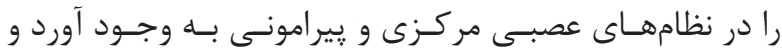

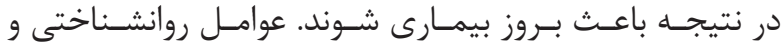

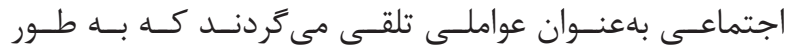

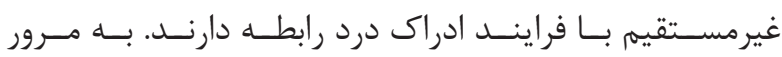

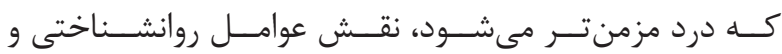

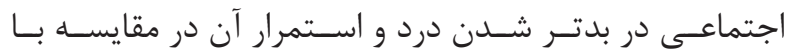

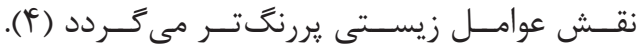

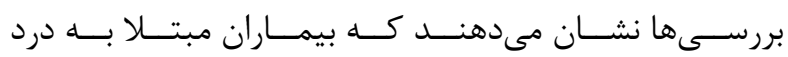

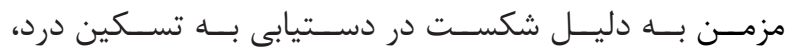

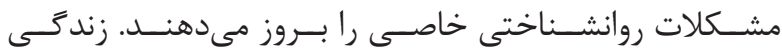

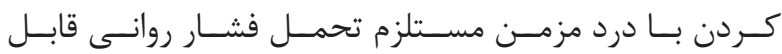

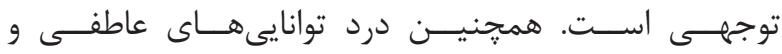

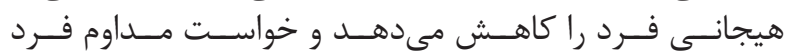

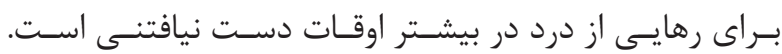

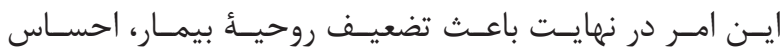

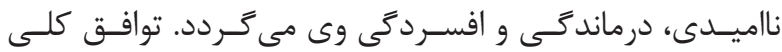

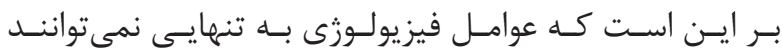

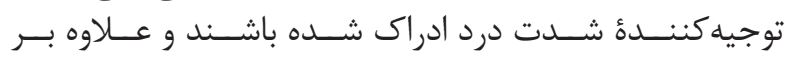

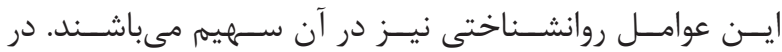

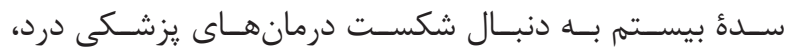

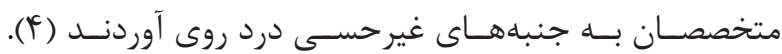

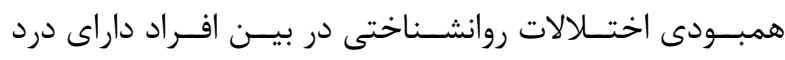

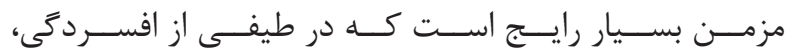

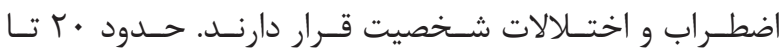

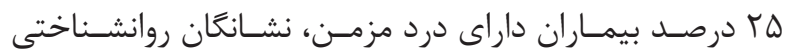

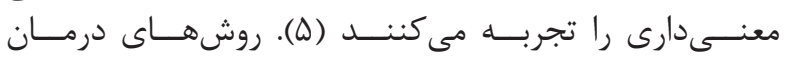

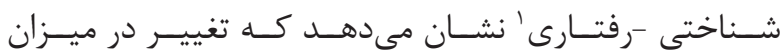

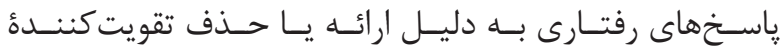

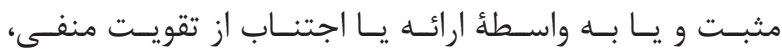

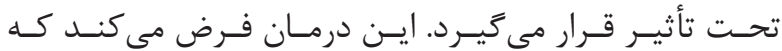

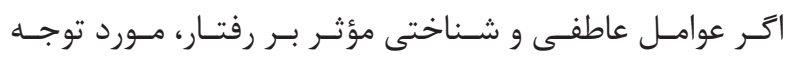

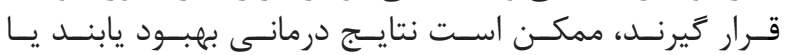


جدول ا- خلاصُٔ مورد بحث در جلسات درمانى با بيماران.

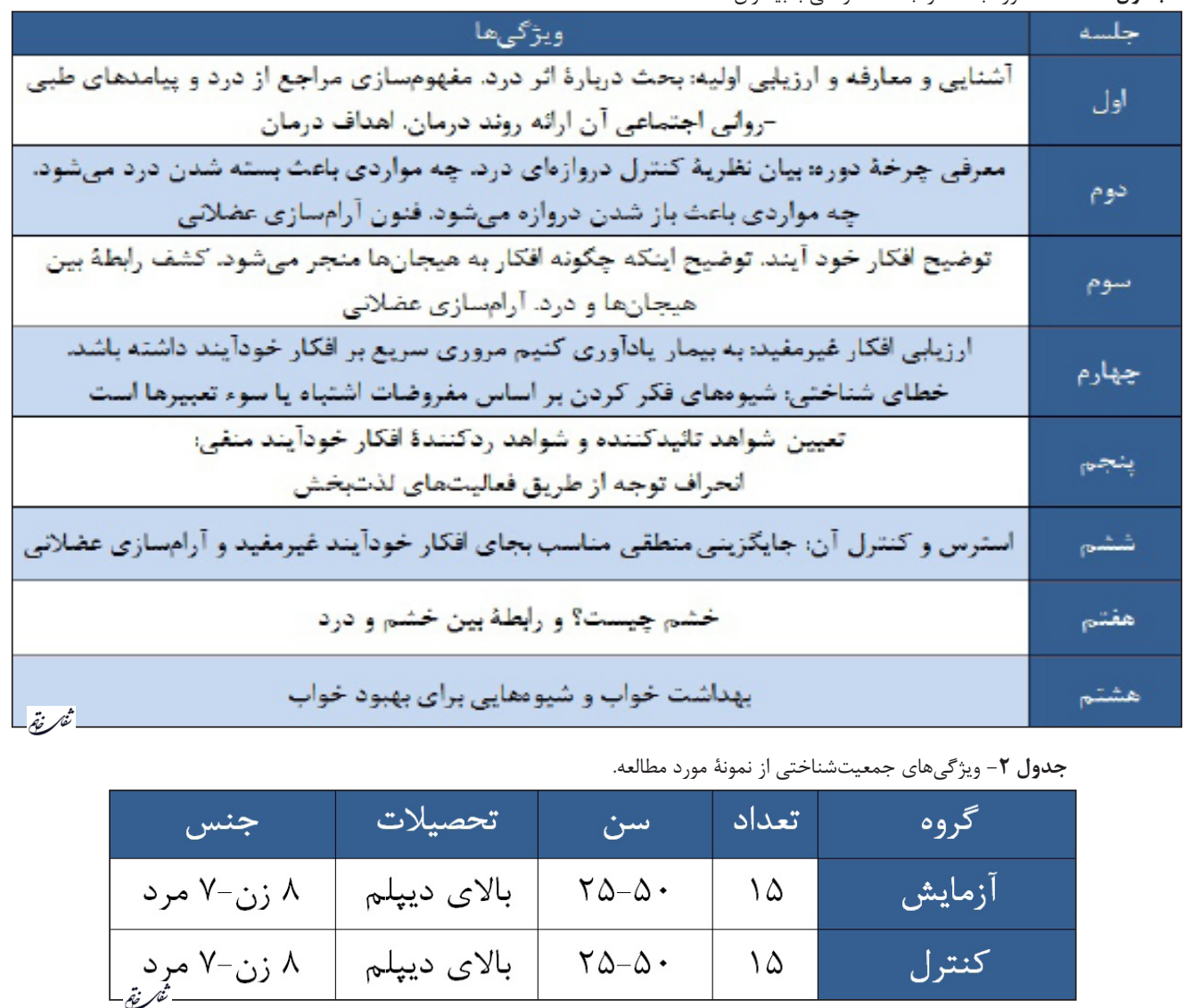

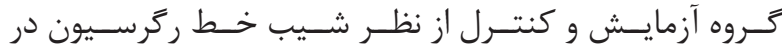

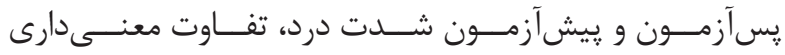

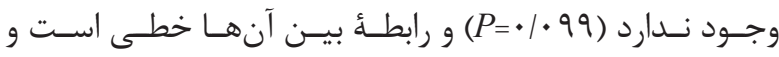

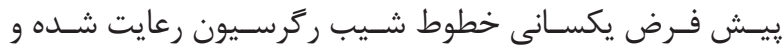

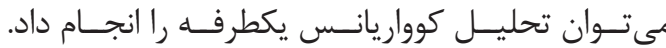

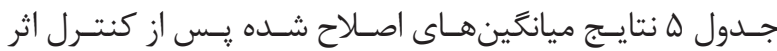

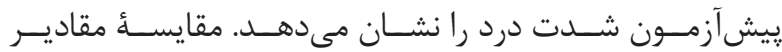

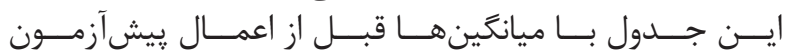

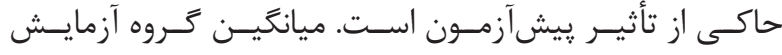

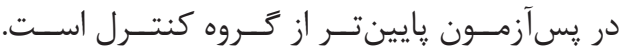

بافتهها بـا اسـتفاده از آزمـون كولموخــروف -اسـميرنوف، طبيعـى بودن

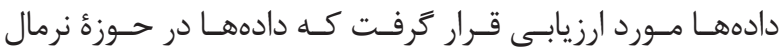

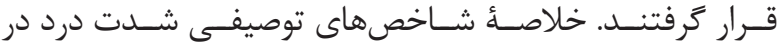

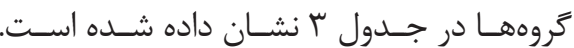

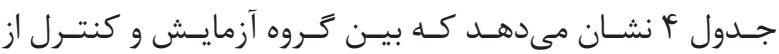

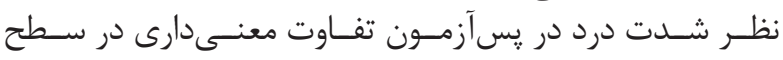

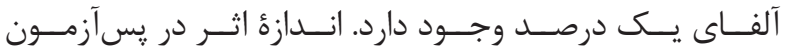

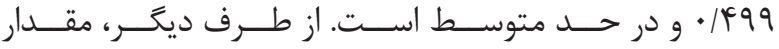

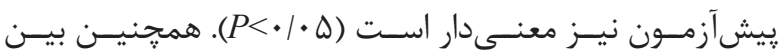

جدول بـ - خلاصٔ شاخصهاى توصيفى شدت درد در كروهها.

\begin{tabular}{|c|c|c|c|c|c|c|}
\hline انحراف معيار & ميانگين & حداكثر & حداقل & تعداد & كروه & \\
\hline $1 / V 9$ & $N / r$ & 1. & f & 10 & ميانگَين شدت درد 1 & \multirow{2}{*}{ آزمايش } \\
\hline $1 / 9 \mathrm{~V}$ & $919 \mathrm{~V}$ & 1. & r & 10 & ميانكين شدت درد ب & \\
\hline T/FF & g/VT & 1. & r & 10 & ميانگَين شدت درد 1 & \multirow{2}{*}{ كنترل } \\
\hline T/DF & G/VT & 1. & $r$ & 10 & ميانگين شدت درد r & \\
\hline
\end{tabular}

\begin{tabular}{|c|c|c|c|}
\hline مجذور اتا & معنى دارى & F & منبع تغييرات \\
\hline $\begin{array}{l}.19 .9 \\
.1 .98\end{array}$ & $\begin{array}{c}. \\
.1 .99\end{array}$ & $\begin{array}{l}\text { TW/IFV } \\
\text { r/qIT }\end{array}$ & مدل اصلاح شده \\
\hline$\cdot 19 \cdot 9$ & - & $T V \cdot / T T V$ & ميانغين شدت درد | \\
\hline $21 \times 99$ & . & rE/9rq & تروه كتترل \\
\hline
\end{tabular}


جدول هـ شاخصهاى توصيفى كروهها در پِّآزمون شدت درد يس از كنترل اثر پيشآزمون.

\begin{tabular}{|c|c|c|c|c|}
\hline \multirow{2}{*}{ ميانگين } & \multirow{2}{*}{ معيار خطا } & \multicolumn{2}{|c|}{ ه9\% فاصله اطمينان } & \multirow{2}{*}{ كروه } \\
\hline & & حد يايين & حد بالا & \\
\hline $41 \cdot .9$ &.$/ 1 \wedge \Delta$ & D/ATG & $g / r \wedge \Delta$ & آزمايش \\
\hline v/rqu & $\cdot / 1 \wedge \Delta$ & $\mathrm{V} / \cdot \mathrm{IQ}$ & V/VVF & كنترل \\
\hline
\end{tabular}

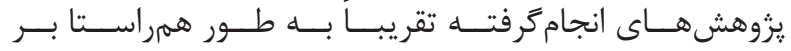

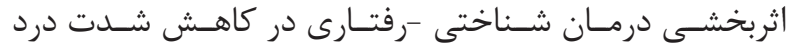

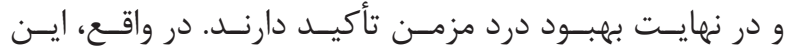

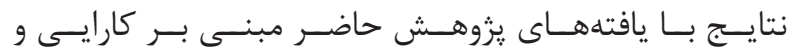

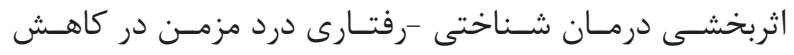

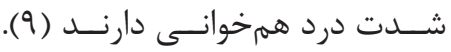

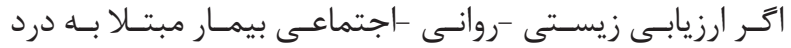

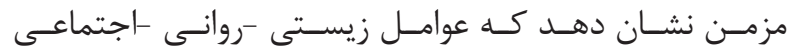

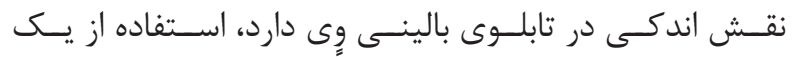

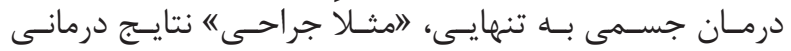

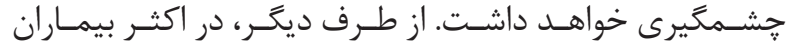

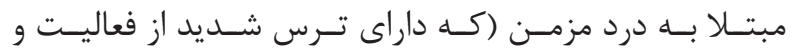

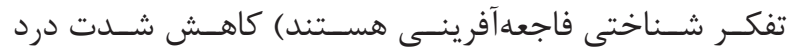

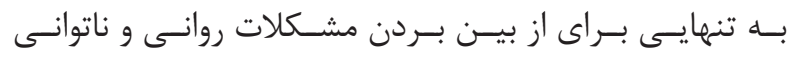

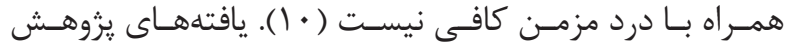

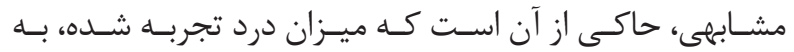

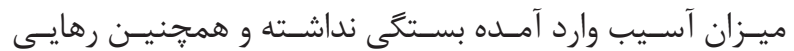

از درد بــه ميـزان داروى مسـكن وابسـته نيسـت (1) (1).

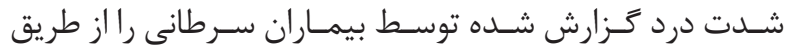

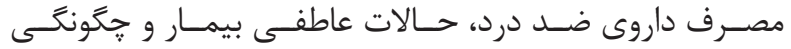

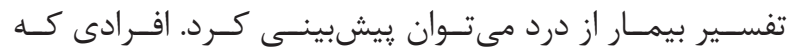

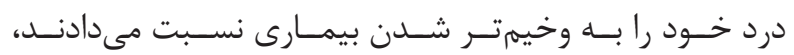

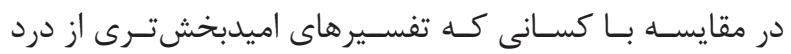

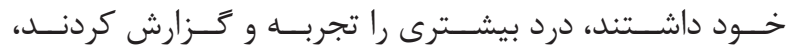

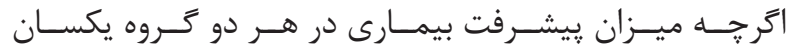

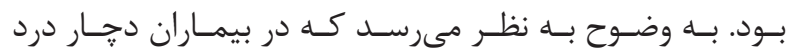

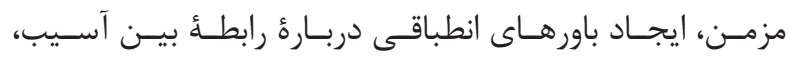

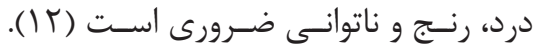

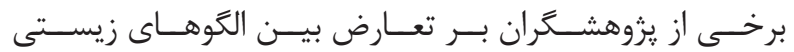

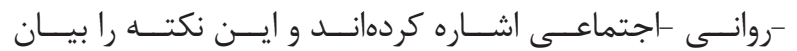

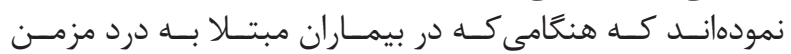

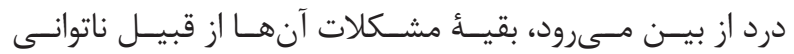

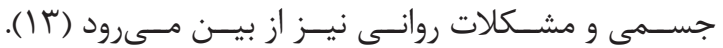

نيكـولاس و اصغـــى بـا اســفاده از روش درمانس، درد بـ بيمـار

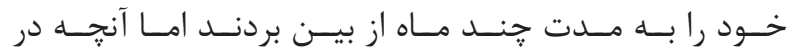

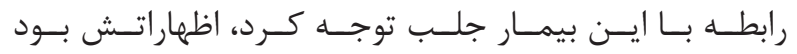

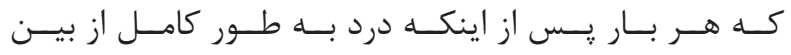

بحث و نتيجه كيرى

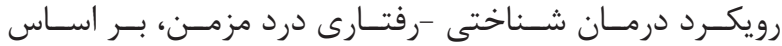

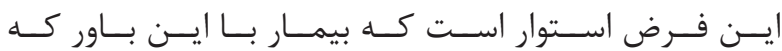

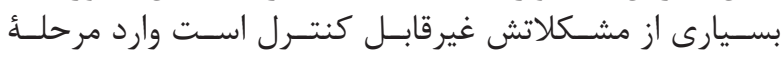

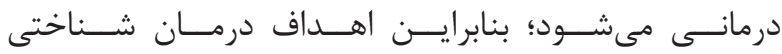

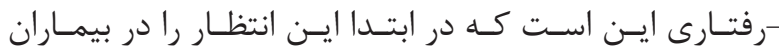

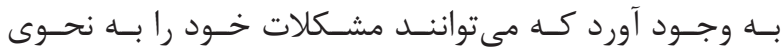

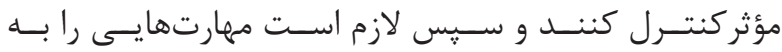

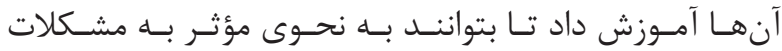

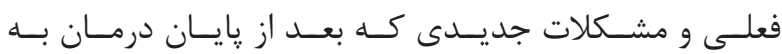

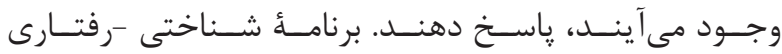

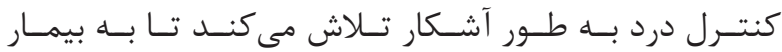

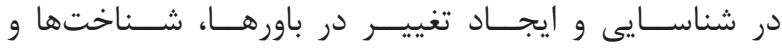

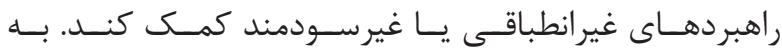

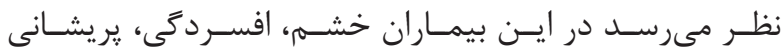

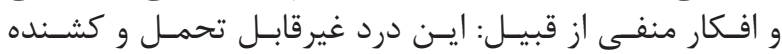

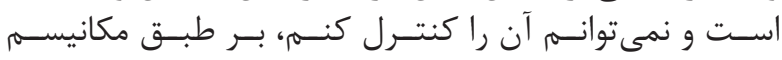

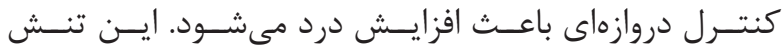

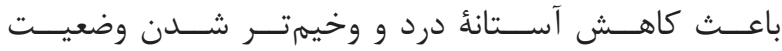

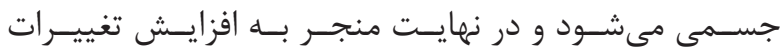

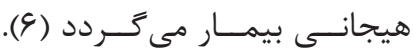

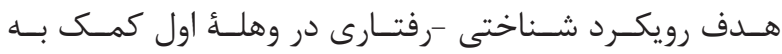

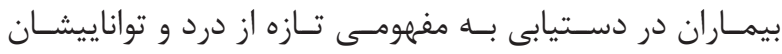

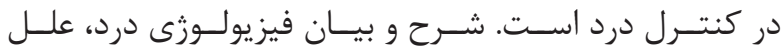

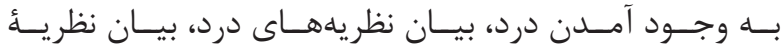

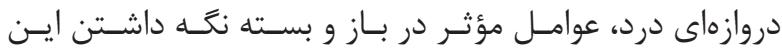

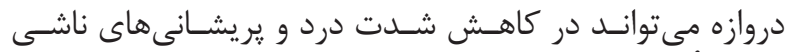

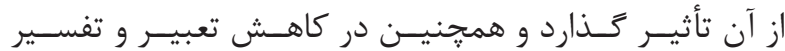

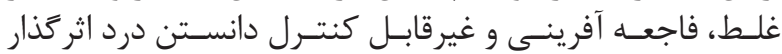

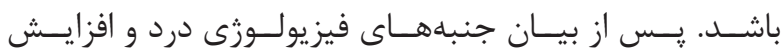

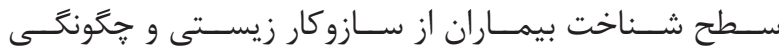

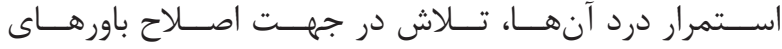

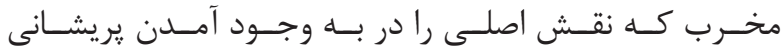

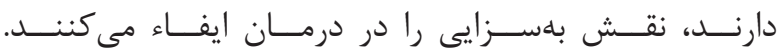

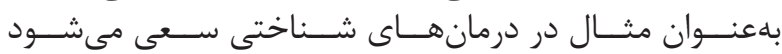

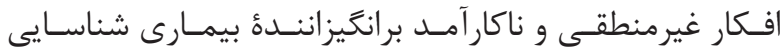

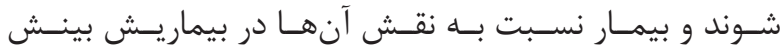

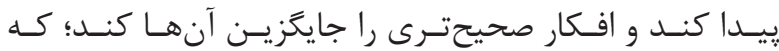

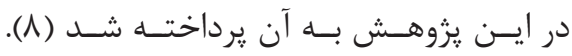




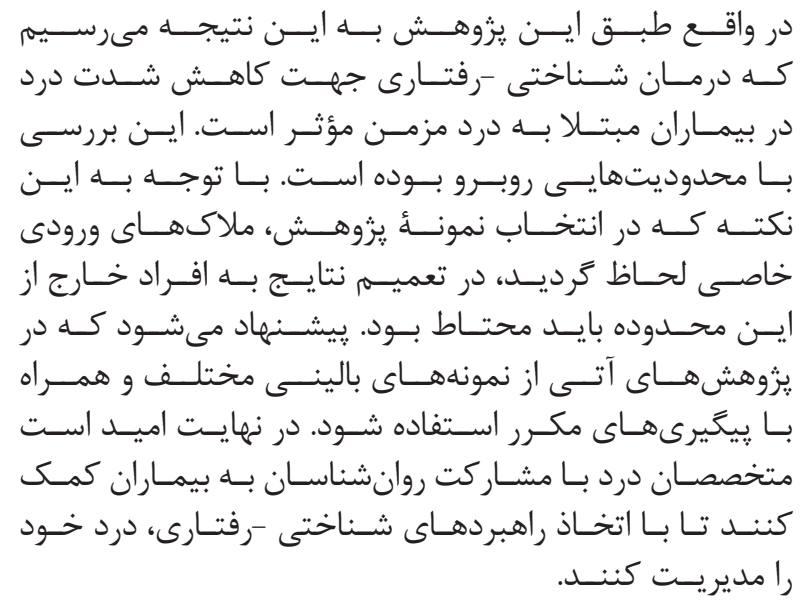

1. Thron BE. Cognitive therapy for chronic pain: step by step guide. NewYork: Guilford Press. 2004; p. 21-165.

2. Asghari Moghadam MA. Pain. Tehran: Roshd Publication. 2012.

3. Jazayeri A. Psychological aspects of pain perception in children. Journal of Rehabilitation. 2004; 2(5): 6470 .

4. Turk DC, Okifuji A. Psychological factors in chronic pain: evolution and revolution. J Consult Clin Psychol. 2002; 70(3): 678-90.

5. Shahani R, Shaeeri MR. Determine the effectiveness of cognitive behavioral therapy to control pain and reduce negative emotions and pain in patients with chronic pain. MS thesis. Ahvaz Shahid Chamran University of Education and Psychology. 2012.

6. Hamid Pour H, Andoz Z. Cognitive therapy techiques. Tehran:Arjmand Publication. 2012.

7. Mirzamani M, Safari A, Holisaz MT, Sadidi A. The effects of pain on life dimensions of chronic pain patients. J Behav Sci. 2007; 1(2):143-53.

8. Hamid Pour H, Andoz Z. The dialectical behavior

$$
\begin{aligned}
& \text { رفتـهـ بـود، وى بــر مصـرف داروهــاى ضـــ درد ادامــه داده و }
\end{aligned}
$$

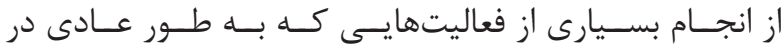

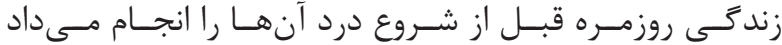

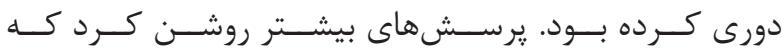

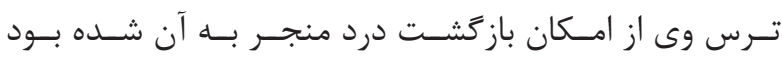

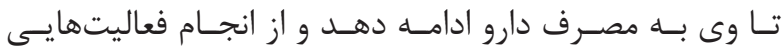

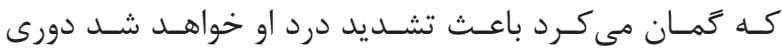

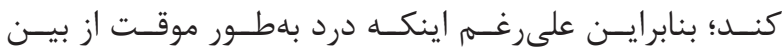

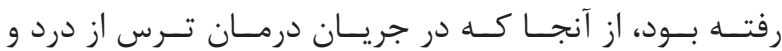

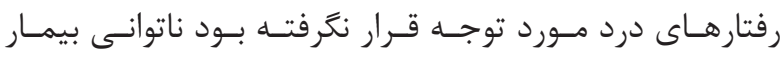

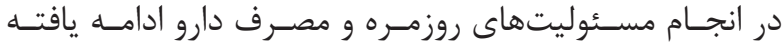

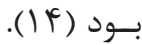

$$
\begin{aligned}
& \text { منابع }
\end{aligned}
$$

therapy. Tehran: Arjmand Publication. 2013.

9. Moloudi R, Fatahi K. Cognitive behavior therapy for chronic medical problems. Tehran: Arjmand Publication. 2012.

10. Sator-Katzenschlager SM, Schiesser AW, KozekLangenecker SA, Benetka G, Langer G, Kress HG. Does pain relief improve pain behavior and mood in chronic pain patients. Anesth Analg. 2003; 97(3): 7917.

11. Hall K, Stride E. The varying response to pain in psychiatricbrit. Brit J Med Psychol. 1952; 27(2): 48-60.

12. Flor H, Turk DC. Chronic back pain and rheumatoid arthritis: predicting pain and disability from cognitive variables. J Behav Med. 1988; 11(3): 251-65.

13. Flor H, Hermann C. Biopsychosocial models of pain. Dworkin RH, Breitbart WS. Psychosocial aspects of pain: a handbook for health care providers. Progress in pain research and management 27. IASP Press. 2004; p. 47-75.

14. Nicholas MK, Asghari A. Investigating acceptance in adjustment to chronic pain: is acceptance broader than we thought? Pain. 2006; 124(3): 269-79. 